\title{
STRUCTURAL STEELS
}

\section{LAWS OF FORMATION OF STRUCTURE AND PROPERTIES IN COLD-DEFORMED LOW-CARBON STRUCTURAL STEEL UNDER INCOMPLETE QUENCHING}

\author{
T. Yu. Barsukova, ${ }^{1}$ D. O. Panov, ${ }^{2}$ and Yu. N. Simonov ${ }^{1}$
}

Translated from Metallovedenie i Termicheskaya Obrabotka Metallov, No. 7, pp. 3 - 9, July, 2021.

\begin{abstract}
The effect of quenching from the intercritical temperature range on formation of martensite-ferrite structure in steel $10 \mathrm{Kh} 3 \mathrm{G} 3 \mathrm{MFS}$ deformed preliminarily by the method of cold radial forging is considered. The microstructure of the steel is studied using optical and scanning electron microscopes. The post-quenching grain size and microhardness of the steel are determined. Tensile and impact bending tests are conducted. The dependence of the mechanical properties of the steel on the quenching mode is described. The diagrams of structural strength are used to show the possibility of formation of different combinations of strength and impact toughness by changing the heating temperature and the time of the isothermal hold in incomplete quenching.
\end{abstract}

Key words: low-carbon alloy steel, cold radial forging, incomplete quenching, intercritical temperature range, grain size, structure, strength, impact toughness.

\section{INTRODUCTION}

Low-carbon steels with multicomponent alloying have found wide application in machine building due to the good structural strength, weldability, and high hardenability in air [1]. One of the directions of optimization of the chemical composition of these steels is replacement of expensive and scarce nickel by manganese and silicon, which is accompanied, however, by some degradation of their ductility and impact toughness [2]. To widen the field of application of nickel-free low-carbon steels with multicomponent alloying, novel modes of their treatment should be developed in order to raise their ductility characteristics at the demanded strength level. The treatment should involve the possibility of control of the set of mechanical properties of these steels.

The structure can be made disperse by successive application of cold plastic deformation and heat treatment. Heat treatment is used for preparing the original structure and for forming the final properties after cold plastic deformation. A cycle of works aimed at studying the effect of cold radial

1 Perm National Research Polytechnic University, Perm, Russia (e-mail: barsukova-chernova.tatyana@mail.ru).

2 Belgorod State National Research University, Belgorod, Russia. forging (CRF) with high degrees of deformation on the structure and properties of steels with initial structure of low-carbon martensite, high-tempered medium-carbon martensite, and martensite-ferrite mixture obtained by incomplete quenching has been performed at the Department of Physical Metallurgy, Thermal and Laser Treatment of the Perm National Research Polytechnic University [3-5]. It has been shown in $[6-8]$ that the stability of substructural boundaries under heating lowers in the case of the use of preliminary cold plastic deformation, which gives rise to cell formation and recrystallization yielding a disperse grain structure. In addition, incomplete quenching makes it possible to control the degree of the $\alpha \rightarrow \gamma$ transformation by varying the heat treatment parameters of the steel $[9,10]$. The present work was connected with the necessity to explain the effect of extremal behavior of impact toughness as a function of the temperature of heating in the intercritical temperature range (ITR) detected for steels with initially martensitic structure [11]. In addition, the effect of incomplete quenching on the structural state and mechanical properties of nickel-free low-carbon steels with multicomponent alloying (for example, for steel 10Kh3G3MFS) remains unexplained. 


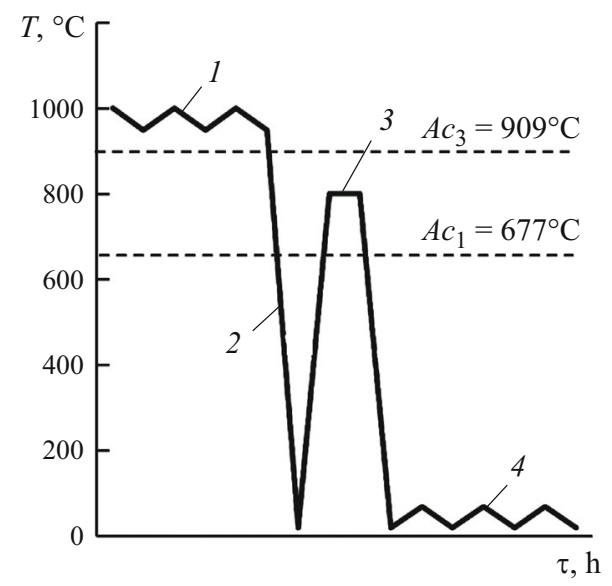

Fig. 1. Cycle of preliminary deformation and heat treatment of steel 10Kh3G3MFS: 1 ) hot forging within $1150-950^{\circ} \mathrm{C} ; 2$ ) air cooling; 3 ) air quenching from $800^{\circ} \mathrm{C} ; 4$ ) cold radial forging with degree of $60 \%$.

The aim of the present work was to determine the laws of formation of structure and properties of steel 10Kh3G3MFS deformed preliminarily by cold radial forging and subjected to incomplete quenching.

\section{METHODS OF STUDY}

We studied steel 10Kh3G3MFS with the following chemical composition (in wt.\%): $0.10 \mathrm{C}, 2.75 \mathrm{Cr}, 2.51 \mathrm{Mn}$, $1.25 \mathrm{Si}, 0.40 \mathrm{Mo}, 0.12 \mathrm{~V}, 0.008 \mathrm{~S}, 0.019 \mathrm{P}$ [12]. Ingots with a mass of $40 \mathrm{~kg}$ from this steel were subjected to free hot forging within $1150-950^{\circ} \mathrm{C}$ with air cooling. Then we conducted incomplete quenching from $800^{\circ} \mathrm{C}(2 \mathrm{~h})$ with air cooling. The subsequent deformation treatment with degree $60 \%$ consisted of CRF in a radial reduction machine with continuous cooling of the deformation source with room-temperature water. The treatment parameters were as follows: the speed of feeding of the billet $180 \mathrm{~mm} / \mathrm{min}$, the speed of its rotation $25 \mathrm{rpm}$, the rate of hammer striking 1000 strikes $/ \mathrm{min}$.

The final heat treatment (incomplete quenching) was conducted in the following modes: charging into hot furnace, holding at 775,800 and $825^{\circ} \mathrm{C}$ for 15,70 and $125 \mathrm{~min}$ at each temperature, and cooling in still air.

The microstructure of the specimens was studied after sample preparation, which involved pressing into conductive resin, grounding with a set of abrasive papers with different grain sizes, and polishing against a cloth with a diamond paste. The surface of the microsections was etched by immersion into a $4 \%$ alcoholic solution of nitric acid. The microstructure was analyzed under an Olympus GX-51 inverted optical microscope at a magnification of $\times 100-\times 1000$ using the Olympus Stream Motion 1.8 software. The grain size in the structure was determined using the SIAMS 700 software. In addition, the microstructure was studied with the help of FEI PHENOM G2 ProX and TESCAN VEGA 3 scanning electron microscopes at a magnification of $\times 1000-\times 50,000$.

The strength and ductility characteristics were determined in tensile tests of specimens of type III-7 according to the GOST 1497-84 Standard using an INSTRON-SATEC 300 LX universal hydraulic system at room temperature and a deformation rate of $1 \mathrm{~mm} / \mathrm{min}$.

The tests for impact bending were conducted for specimens with a stress concentrator in the form of a crack (No. 17 in GOST 9454-78) at room temperature using a TE JB-300B impact pendulum. The geometrical parameters of the fractured specimens were determined using an Olympus SZX-16 binocular stereomicroscope and the Olympus Stream Motion 1.8 software.

The hardness of the specimens was determined by the Vickers method according to GOST 2999-75 using an IT 5010 device at a load of $5 \mathrm{kgf} / \mathrm{mm}^{2}$.

\section{RESULTS AND DISCUSSION}

\section{Preliminary Treatment and Initial Structure of Steel 10Kh3G3MFS}

Steel 10Kh3G3MFS with system multicomponent alloying exhibits high stability of supercooled austenite and hardens in air in sections of up to $100 \mathrm{~mm}$. The preliminary heat treatment of the steel consisted of double quenching with lowering of the heating temperature (Fig. 1). Figure 2 presents the structure of the steel after quenching and deformation by different modes. The structure formed due to complete quenching combined with hot forging was represented by low-carbon lath martensite (Fig. $2 a$ ). Subsequent holding in the ITR at $800^{\circ} \mathrm{C}$ and cooling in air yielded freshly hardened lath martensite with some retained austenite and separate regions of matrix $\alpha$-phase (Fig. $2 b$ ). This structure provided a strength level similar to that of the steel with totally martensitic structure and an elevated impact toughness [11]. The deformation treatment was cold radial forging. The microstructure in the cross section of the billet exhibited distortion of the earlier linear substructural components (Fig. 2c). The structure in the longitudinal section had an orientation (Fig. $2 d$ ). By the data of the transmission electron microscopy (TEM), the longitudinal section had a banded [5] structure represented by former martensite laths oriented over the axis of the billet [5].

\section{Formation of Microstructure under Incomplete Quenching}

We chose the temperature for incomplete quenching from the upper part of the ITR, i.e., 775,800 and $825^{\circ} \mathrm{C}$. The time of the hold at the heating temperature was 15,70 and $125 \mathrm{~min}$. The structure of the steel after the incomplete quenching is presented in Fig. 3. After the heat treatments chosen, we obtained steel 10Kh3G3MFS in nine conditions differing in the proportion of the freshly formed martensite 

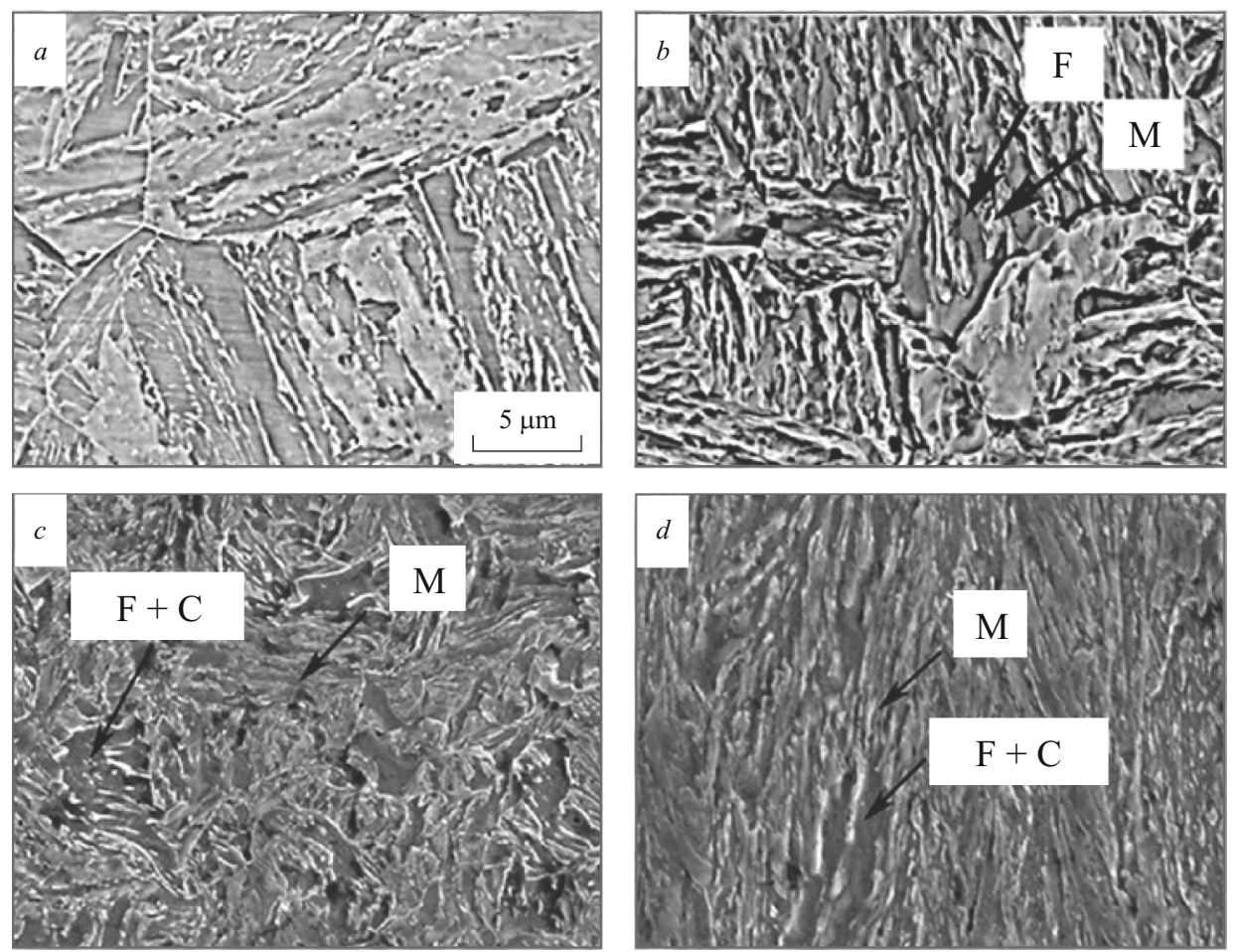

Fig. 2. Microstructure (SEM) of steel 10Kh3G3MFS after air cooling from the temperatures of hot forging $(a)$, incomplete quenching $(b)$ and cold radial forging $(c, d): a-c$ ) cross section of the billet; $d$ ) longitudinal section; F) ferrite; M) martensite; C) carbide.
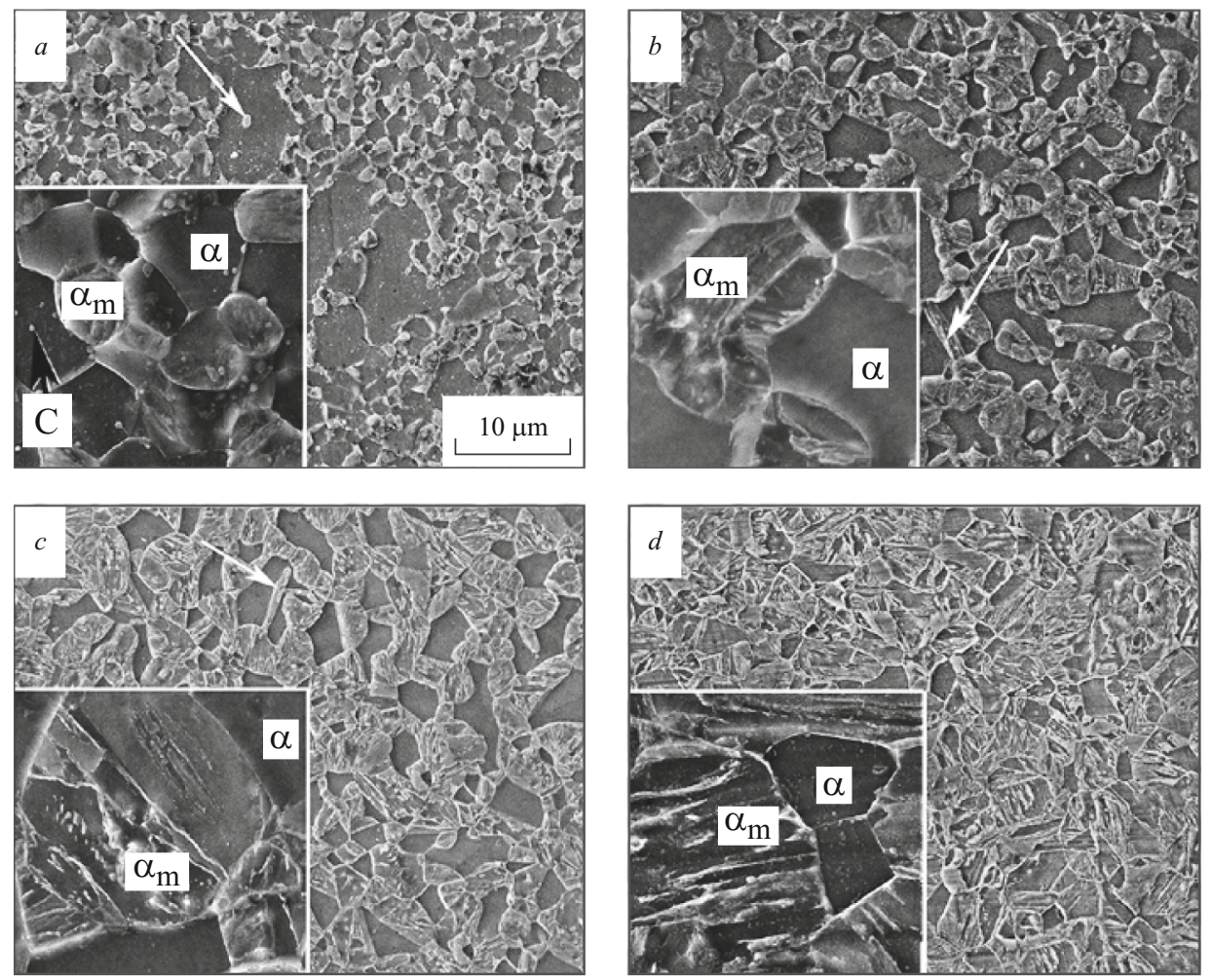

Fig. 3. Microstructure of steel 10Kh3G3MFS (the inserts give 5-fold magnification) after incomplete quenching from $775^{\circ} \mathrm{C}(a), 800^{\circ} \mathrm{C}(b, c)$ and $\left.860^{\circ} \mathrm{C}(d): a, b\right) 5$-min heating for quenching; $c, d)$ 125-min heating; $\alpha_{\mathrm{m}}$ ) martensite; $\alpha$ ) matrix $\alpha$-phase; C) carbide; the arrows point at austenite regions with lamellar morphology, which have transformed into martensite. 

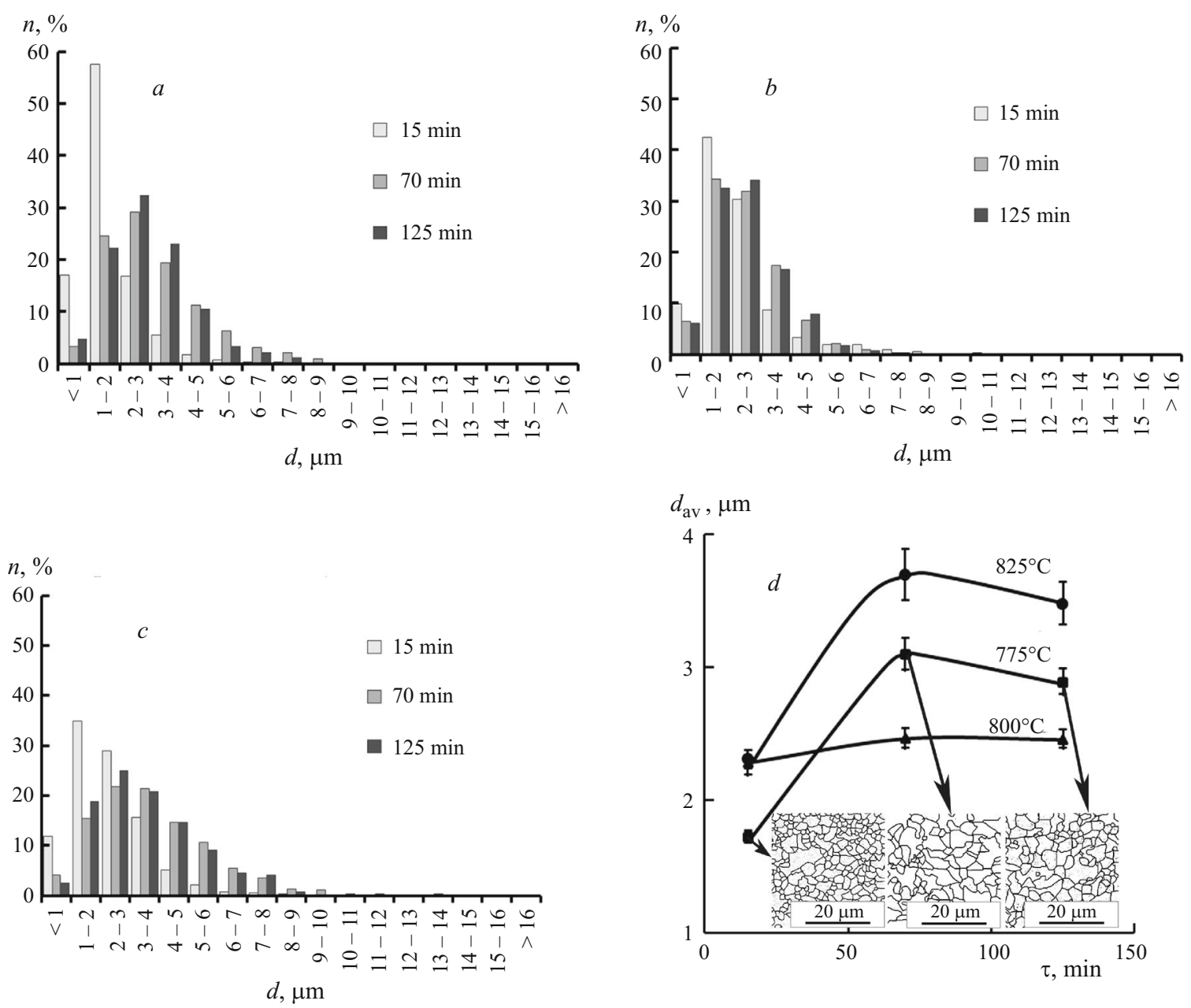

Fig. 4. The grain size distribution ( $n$ is the relative fraction of the cases) in the structure of steel 10Kh3G3MFS after incomplete quenching from $775^{\circ} \mathrm{C}(a), 800^{\circ} \mathrm{C}(b)$ and $825^{\circ} \mathrm{C}(c)$ and dependence of the average grain size on the duration of the hold $(15,70$ and $125 \mathrm{~min})$ at the temperatures of heating for quenching $(d)$.

$\alpha_{m}$ (the light regions in Fig. 3) to the preserved $\alpha$-phase (the dark regions in Fig. 3). The structure of the specimens quenched from $775^{\circ} \mathrm{C}$ contains some coarse grains of the initial $\alpha$-phase virtually not involved into the transformation and numerous fine grains (Fig. $3 a$ ). The matrix $\alpha$-phase contains carbide particles, the content of which decreases with prolongation of the isothermal hold during the quenching. Regions of "fresh" martensite have an equiaxed shape and are arranged in the matrix $\alpha$-phase primarily on its boundaries. In some cases, elongated regions of "fresh" martensite (marked with the arrow in Fig. $3 a$ ) are observed in the volume of the matrix $\alpha$-phase due to preservation of boundaries of the initial martensite $[13,14]$. Elevation of the temperature of heating for quenching to $800^{\circ} \mathrm{C}$ promotes growth of the areas of the regions of transformed austenite. The martensite newly formed under the cooling is arranged in chains over the boundaries of matrix grains or forms clusters and thin plates inside them (Fig. $3 b$ and $c$ ). The regions of the matrix $\alpha$-phase now have no common boundaries and are separated by martensite regions (Fig. $3 b$ and $c$ ), i.e., the structure of the steel acquires a martensite skeleton. After the incomplete quenching from $825^{\circ} \mathrm{C}(125 \mathrm{~min})$, the structure of lath martensite with a low content of preserved $\alpha$-phase is homogeneous over the cross section of the specimen (Fig. $3 d$ ). When the temperature and the hold time during the heating for quenching are increased, the area taken by martensite grows, and its internal structure is manifested better.

The quantitative metallographic analysis of the grain structure of steel $10 \mathrm{Kh} 3 \mathrm{G} 3 \mathrm{MFS}$ in nine conditions has shown that the parameters of heating and holding in the ITR affect the grain size in a complex manner (Fig. $4 a-c$ ). Preliminary cold plastic deformation by CRF conducted before the incomplete quenching provides formation of a fine-grained structure with grain size $1-5 \mu \mathrm{m}$ in steel 10Kh3G3MFS (Fig. $4 a-c$ ).

It seems interesting to assess the effect of the heating temperature on the average grain size. We established that the isothermal holds in the ITR for 15 and 125 min increased the average grain size (Fig. $4 d$ ). However, the intermediate 
hold time of $70 \mathrm{~min}$ at 775 and $825^{\circ} \mathrm{C}$ produced an effect of local growth of the grain size. Incomplete quenching from $800^{\circ} \mathrm{C}$ with virtually any hold kept the grain size at about $2.4 \mu \mathrm{m}$ (Fig. $4 b$ and $d$ ). Thus, the average grain size after the hold for 125 min was minimal at the heating temperature of $800^{\circ} \mathrm{C}$ and amounted to $2.48 \pm 0.08 \mu \mathrm{m}$. After the quenching from 775 and $285^{\circ} \mathrm{C}$ the average grain size was $2.89 \pm 0.09 \mu \mathrm{m}$ and $3.48 \pm 0.16 \mu \mathrm{m}$ respectively.

\section{Mechanical Properties after Incomplete Quenching}

We determined the characteristics of mechanical properties of the steel in nine conditions. The values obtained were approximated by second-order regression equations within factor design of experiment [15], i.e.,

$$
\begin{gathered}
\sigma_{\mathrm{r}}=-37311+45.438 \tau+86.103 T- \\
0.04909 \tau T-0.0298 \tau^{2}-0.048 T^{2} ; \\
\sigma_{0.2}=-41610+50.4 \tau+97.48 T- \\
0.0564 \tau T-0.0231 \tau^{2}-0.056 T^{2} ; \\
\delta=704.6-1.89 \tau-1.357 \mathrm{~T}+ \\
0.002182 \tau T+0.000826 \tau^{2}+0.004 T^{2} ; \\
\psi=2868.97-2.767 \tau-6.7024 \mathrm{~T}+ \\
0.00327 \tau T+0.000826 \tau^{2}+0.004 T^{2},
\end{gathered}
$$

where $\sigma_{\mathrm{r}}$ is the ultimate strength in $\mathrm{MPa}, \sigma_{0.2}$ is the conventional yield strength in $\mathrm{MPa}, \delta$ is the elongation in $\%, \psi$ is the contraction in $\%, \tau$ is the duration of the isothermal hold in min, and $T$ is the heating temperature in ${ }^{\circ} \mathrm{C}$. The models are valid for the heating temperature of $775-825^{\circ} \mathrm{C}$ and the hold time of $15-125 \mathrm{~min}$.

The results of the computations by formulas (1) - (4) allow us to plot the dependences of the mechanical properties of the material for the specified boundary conditions (Fig. 5). It should be noted that the experimental and computed values may differ somewhat due to the approximation. For example, the relative deviation of the computed data from the experimental results for the nine conditions studied varies within $0-7 \%$ for the ultimate strength, $0-5 \%$ for the conventional yield strength, $2-7 \%$ for the elongation, and $1-6 \%$ for the contraction. These data should be allowed for when describing the obtained dependences of the characteristics on the total effect of the heat treatment parameters.

When plotting the mathematical factor models, we established that the temperature and time parameters had a dominant influence. The characteristics of the hardness and of the ultimate strength, as well as the elongation, were determined to a great degree by the temperature of heating for quenching. The conventional yield strength depended on the heating temperature and on the time of the hold to the same degree. The contraction was determined by the factor of interaction between the temperature and the time.

The surfaces plotted (Fig. 5) reflect the effect of the heat treatment parameters on the properties of the steel. Growth of the heating temperature and prolongation of the hold are accompanied by growth of the volume fraction of freshly hardened martensite and provide elevation of the strength characteristics and lowering of the elongation (Fig. $5 a-c$ ). The contraction (Fig. $5 d$ ) varies over a curve with two maximums after the incomplete quenching from $775^{\circ} \mathrm{C}(15 \mathrm{~min})$ and $825^{\circ} \mathrm{C}(125 \mathrm{~min})$.

We have not managed to plot an empirical function for the impact toughness, because in the temperature and time ranges studied this characteristic depended on the parameters of the incomplete quenching in a more complex manner (Fig. 5e). As a rule, the growth of the strength characteristics was accompanied by lowering of the reliability of the material. For steel $10 \mathrm{Kh} 3 \mathrm{G} 3 \mathrm{MFS}$ this occurred upon prolongation of the hold at 775 and $825^{\circ} \mathrm{C}$ in the incomplete quenching (Fig. $5 a$ and $e$ ). However, the study of the treatment with heating at $800^{\circ} \mathrm{C}$ has shown an anomaly, i.e., increase in the level of the impact toughness and formation of a local maximum after the hold for $125 \mathrm{~min}$. This effect is explainable by formation of a more fine-grained structure than after the quenching from 775 and $825^{\circ} \mathrm{C}$, as it has been shown earlier (Fig. 4d).

The diagrams of the structural strength of steel 10Kh3G3MFS (Fig. 6) reflect the wide possibility of varying the combination of mechanical properties by changing the parameters of incomplete quenching. The proportion of the ultimate strength to the elongation denoted by points $4 a, 4 b$, $4 c$ in Fig. $6 a$ shifts linearly to the right and to the bottom with increase of the temperature of heating for quenching. The proportion of the characteristics of the impact strength to the ultimate strength (Fig. $6 b$ ) shifts first to the right and to the top, which corresponds to simultaneous growth of the characteristics of the strength and impact toughness. However, the incomplete quenching from $825^{\circ} \mathrm{C}$ causes shifting of the point in the diagram to the right and to the bottom due to formation of a coarser structure.

\section{CONCLUSIONS}

1. Steel 10Kh3G3MFS deformed by the method of cold radial forging and then subjected to incomplete quenching from the upper part of the intercritical temperature range acquires austenite arranged primarily over boundaries of the former matrix $\alpha$-phase in the form of equiaxed grains and inside individual regions of the matrix. The structure formed as a result of such quenching is a fine-grained one and consists of fine regions of preserved $\alpha$-phase, carbides and freshly formed martensite.

2. After the cold radial forging and quenching from $800^{\circ} \mathrm{C}$ the average grain size is much smaller than after the quenching from 775 and $825^{\circ} \mathrm{C}$. A fine-grained structure forms in the steel after a 70 -min hold at $800^{\circ} \mathrm{C}$ and is preserved when the hold is prolonged to $125 \mathrm{~min}$.

3 . Increase of the heating temperature and prolongation of the hold during incomplete quenching is accompanied by 

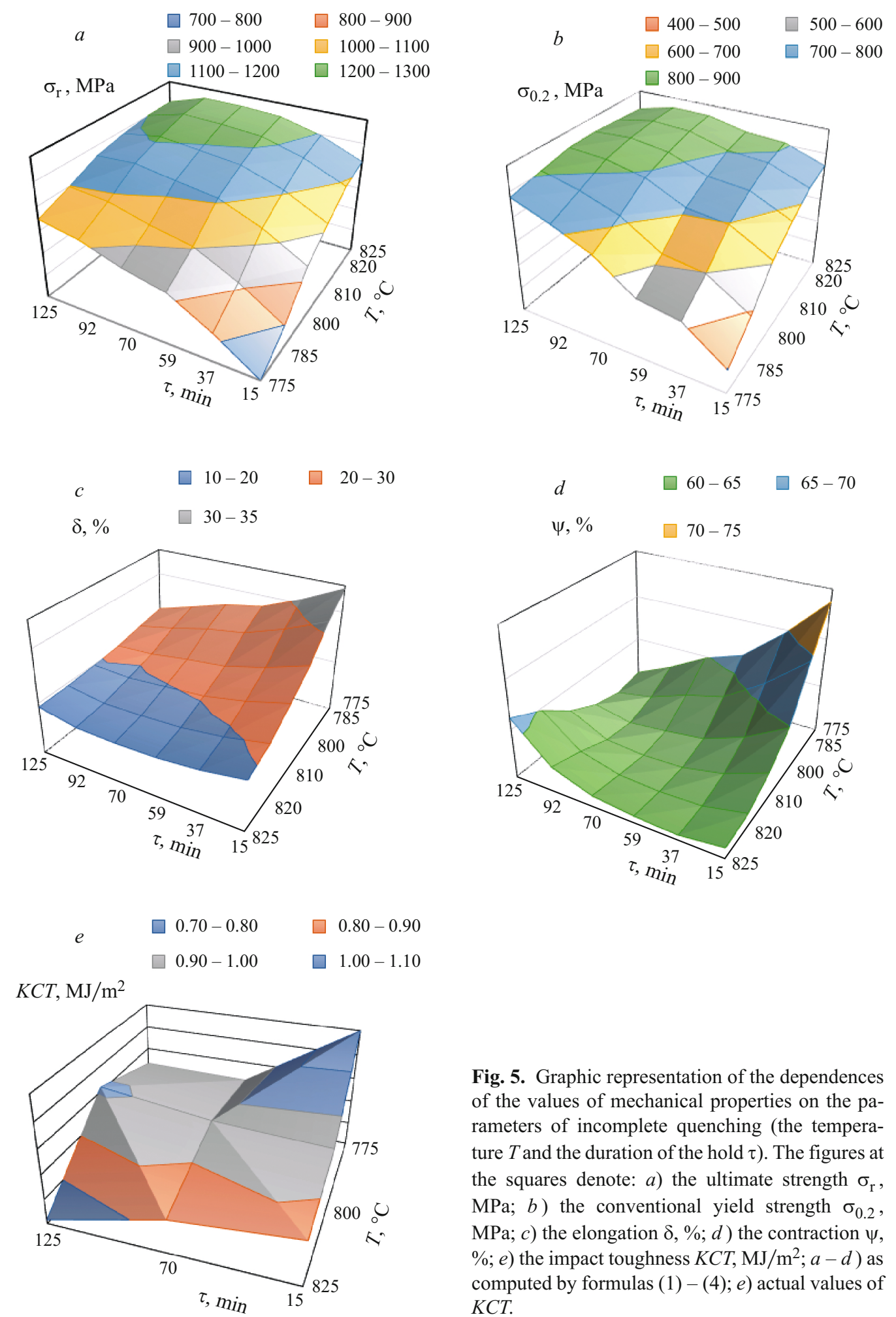

growth of the volume fraction of freshly formed martensite and results in growth of the strength characteristics and lowering of the elongation. The contraction varies with formation of two maximums after the incomplete quenching at $775^{\circ} \mathrm{C}$ for $15 \mathrm{~min}$ and $825^{\circ} \mathrm{C}$ for $125 \mathrm{~min}$.

Fig. 5. Graphic representation of the dependences of the values of mechanical properties on the parameters of incomplete quenching (the temperature $T$ and the duration of the hold $\tau$ ). The figures at the squares denote: $a$ ) the ultimate strength $\sigma_{\mathrm{r}}$, $\mathrm{MPa} ; b)$ the conventional yield strength $\sigma_{0.2}$, $\mathrm{MPa} ; c)$ the elongation $\delta, \% ; d$ ) the contraction $\psi$, $\%$; e) the impact toughness $K C T, \mathrm{MJ} / \mathrm{m}^{2} ; a-d$ ) as computed by formulas (1) - (4); e) actual values of $K C T$.

4. The study of the effect of the modes of incomplete quenching on the impact toughness has shown an anomalous behavior, i.e., elevation of the level of the impact toughness and formation of a local maximum after the quenching from $800^{\circ} \mathrm{C}$ for $125 \mathrm{~min}$. This effect is explainable by formation 

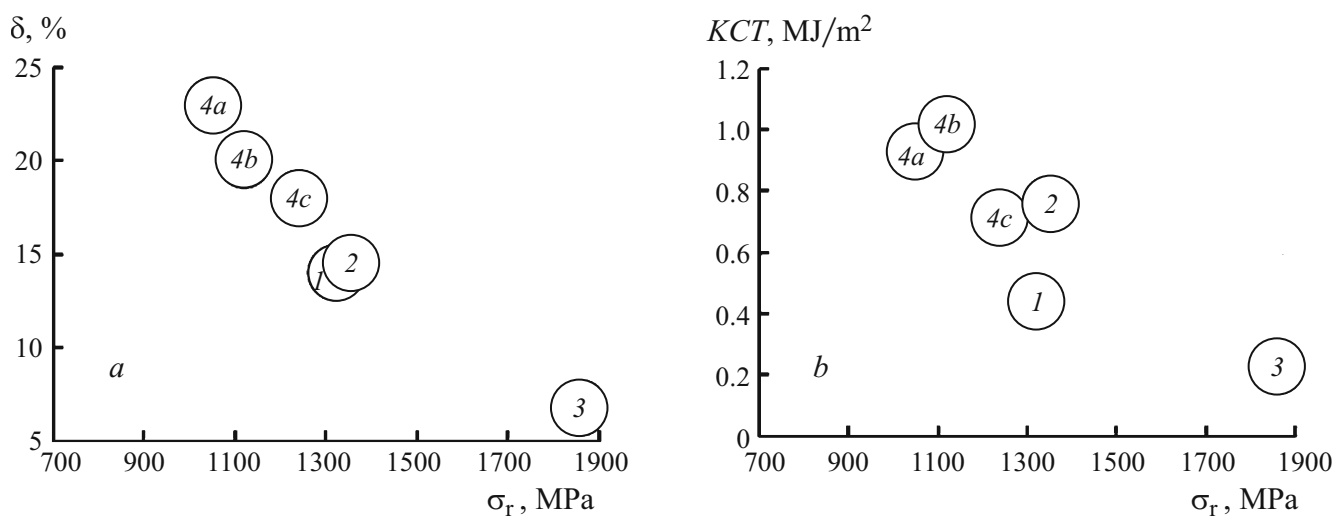

Fig. 6. Diagrams of structural strength of steel 10Kh3G3MFS in various conditions: 1 ) hot forging with air cooling; 2$)$ incomplete quenching from $800^{\circ} \mathrm{C}(120 \mathrm{~min})$ in air; 3$)$ cold radial forging with degree $60 \% ; 4 a, 4 b, 4 c$ ) incomplete quenching in air after a hold for $125 \mathrm{~min}$ at 775,800 and $825^{\circ} \mathrm{C}$, respectively.

of a more fine-grained structure than after the quenching from 775 and $825^{\circ} \mathrm{C}$.

5. The most favorable combination of the ultimate strength and impact toughness has been obtained after the 125 -min quenching from $800^{\circ} \mathrm{C}\left(\sigma_{\mathrm{r}}=1120 \mathrm{MPa}, K C T=\right.$ $\left.1.02 \mathrm{MJ} / \mathrm{m}^{2}\right)$ and after the 125 -min quenching from $825^{\circ} \mathrm{C}$ $\left(\sigma_{\mathrm{r}}=1240 \mathrm{MPa}, K C T=0.72 \mathrm{MJ} / \mathrm{m}^{2}\right)$.

The study has been performed with financial support of the Ministry of Education of Russia within implementation of the program of activities of the world-level scientific and educational center "Rational Use of Mineral Resources".

\section{REFERENCES}

1. Yu. N. Simonov, M. Yu. Simonov, D. P. Poduzov, et al., "Transformations, structure and properties of system-alloyed low-carbon nickel-free steels," Metal Sci. Heat Treat., 54(11-12), $558-564$ (2013).

2. Yu. N. Simonov, M. Yu. Simonov, D. P. Poduzov, et al., "Transformations, structure and properties of system-alloyed low-carbon nickel-free steels," Metalloved. Term. Obrab. Met., No. 11(689), 4 - 11 (2012).

3. A. N. Balakhnin, D. O. Panov, M. G. Titova, et al., "Effect of cold plastic deformation by radial forging and subsequent heat treatment on the structure and properties of steel 10Kh3G3MF," Metalloved. Term. Obrab. Met., No. 11(689), 22 - 27 (2012).

4. A. S. Pertsev, D. O. Panov, Yu. N. Simonov, and A. I. Smirnov, "Formation of structure and mechanical properties of structural steel under cold plastic deformation by radial forging," Obrab. Met. (Tekhnol., Oborud., Instrum.), No. 1, 32 - 38 (2014).

5. T. Barsukova, D. Panov, A. Pertsev, et al., "Evolution of structure and properties of multiphase low-carbon steel during cold radial forging," Met. Sci. Heat Treat., 61 (2020) (DOI: 10.1007/s11041-020-00468-6).

6. M. Tokizane, N. Matsumura, K. Tsuzaki, et al., "Recrystallization and formation of austenite in deformed lath martensitic structure of low carbon steels," Metall. Trans. A, 13, 1379 - 1388 (1982) (DOI: 10.1007/BF02642875).

7. D. O. Panov and A. I. Smirnov, "Features of austenite formation in low-carbon steel upon heating in the intercritical temperature range," Phys. Met. Metallogr., 118(11), 1081 - 1090 (2017).

8. F. Manuel, C. Cerda, B. Schulz, et al., "The effect of ultrafast heating on cold-rolled low carbon steel: formation and decomposition of austenite," Metals, 6(12), 321 (2016) (DOI: 10.3390/met6120321).

9. S. Imtiaz, A. Muhammad, and B. Muhammad, "Effect of intercritical heat treatment on mechanical properties of plain carbon dual phase steel," Mehran Univ. Res. J. of Eng. and Technol., 37(1), $149-158$ (2018).

10. L. V. Long, D. V. Hien, N. T. Thanh, et al., "Impact of cold-rolling and heat treatment on mechanical properties of dual-phase treated low carbon steel," Adv. Mater. Sci. Eng. [open access], ID1674837 (2020) (DOI: 10.1155/2020/1674837).

11. D. Panov, T. Barsukova, A. Smirnov, et al., "Intercritical quenching of low-carbon steel with the formation of a disperse multiphase structure," Metal Work. Mater. Sci., 4, 6 - 18 (2017) (DOI: 10.17212/1994-6309-2017-4-6-18).

12. Yu. N. Simonov, M. Yu. Simonov, G. S. Shaimanov, and D. P. Poduzov, "Steel for fabricating articles with enhanced hardenability, Patent RF, MPK C 22 C 38/38," Byull. Izobr. Polezn. Modeli, No. 31 (2014), appl. 26.03.2013, publ 10.11.2014.

13. S. Q. Yuan, Z. J. Xie, J. Wang, et al., "Effect of heterogeneous microstructure on refining austenite grain size in low alloy heavy-gage plate," Metals, 10(1), 132 (2020) (DOI: 10.3390/ met10010132).

14. A. N. Makovetskii, T. I. Tabatchikova, I. L. Yakovleva, et al., "Structure formation in low-alloy pipe steel during heating in the intercritical temperature range," Phys. Met. Metallogr., 113(7), 704 - 715 (2012) (DOI: 10.1134/S0031918X12070083).

15. T. Yu. Barsukova, D. O. Panov, and M. Yu. Simonov, "Formation of superfine-grained ferritic-martensitic structure in low-carbon structural steel under quenching from the intercritical temperature range," Tekhnol. Met., No. 11, 2-12 (2019). 